\title{
Dose and duration dependent toxicity of Dioxin $(2,3,7,8$ TCDD) to few lysosomal enzymes in mice kidney
}

\author{
Jyoti Jigyasi ${ }^{1}$ and Rahul Kundu ${ }^{2 *}$ \\ 1,2 (Department of Biosciences, Saurashtra University, Rajkot-360005, Gujarat State, India)
}

\begin{abstract}
TCDD, a highly toxic lipophilic Dioxin, causes many health problems in animals including human when exposed through dietary intake of fat. Present communication reports in vivo dose and exposure duration dependent cellular toxicity of environmentally available concentration of TCDD to few lysosomal enzymes in mice kidney. The study tests two hypotheses (a) environmentally available low concentration of TCDD provokes dose and exposure duration dependent toxic effects to lysosomal enzymes and, (b) Low dose TCDD exposure may trigger cellular apoptosis by altering different lysosomal enzymes. Groups of female Swiss albino mice were subjected to different concentration of TCDD $(0.004 \mathrm{mg} / \mathrm{kg} \mathrm{bw} / \mathrm{d}, 0.04 \mathrm{mg} / \mathrm{kg} \mathrm{bw} / \mathrm{d})$ by oral gavage for 2,4 and 6 days of exposure duration. The observed results suggested that significantly dose and exposure duration dependent effects were found in kidney cells of mice. The results indicate TCDD possibly causing oxidative stress and disturb cell homeostasis by increasing intracellular ions. ROS and increased ions may be responsible for the alteration of different physiological activity of cell. Though the exact process is not clear at present, but it is also possible that altered functions of key lysosomal enzymes might have evoked the process of cell destruction and cell apoptosis.
\end{abstract}

Keywords: Dioxin, TCDD, dose and duration dependent effects, lysosomal enzymes, kidney, mice

\section{Introduction}

TCDD is one of the most toxic congener of dioxin family that has low degradable capacity and high bioavailability. TCDD induced cell death was reported as a consequences of loss of body weight (Wasting syndrome) and inhibition of gluconeogenesis with appetite suppression ${ }^{[1]}$. TCDD exposure caused hemorrhagic cystitis and focal pyelonephritis in an exposed child ${ }^{[2]}$. TCDD was reported to affect the variety of enzymes like Uridine diphosphate, Glucuronosyl transferase and multi-functional enzyme systems involved in detoxification and metabolism of a wide variety of endogenous and exogenous compounds. It was also reported that an apparent structure activity relationship were found between the located hydrogen atom on TCDD molecules and the activity inducing factor of other enzymes in in vivo and in vitro conditions ${ }^{[3,4]}$. Kidney being an excretory organ of living organism, accumulation of waste toxic products occurs into the renal cells and proximal convoluted tubules. TCDD intake by human beings occurs primarily via food products such as milk, dairy products. The metabolites of organochlorine may be responsible for renal cellular damage ${ }^{[5]}$. It was reported earlier that TCDD induces oxidative and energy stress to the developed chicken kidney ${ }^{[6]}$. Dysregulation of autophagy process in cell had been found to be linked with pathogenesis of renal disease. Recent studies showed clear evidences of TCDD induced significant cell proliferation and signs of apoptosis but indicated no activation of relevant caspases like caspase 8,9 or $3^{[7]}$. It has been reported previously that TCDD causes major urinary problems, however, histological studies showed no renal lesions ${ }^{[8]}$. Going through the literature it was observed that studies on the toxic effects of TCDD to lysosome is rare. Therefore, the present study was undertaken to assess the dose and duration dependent effects of a dioxin TCDD to few key lysosomal enzymes in mice kidney. The study tests two hypotheses (a) environmentally available low concentration of TCDD provokes dose and exposure duration dependent toxic effects to lysosomal enzymes and, (b) Low dose TCDD exposure may trigger cellular apoptosis by altering different lysosomal enzymes.

\section{Materials And Methods}

Inbred healthy female Swiss albino mice, around 3 months of age and weighing $30 \pm 5 \mathrm{~g}$, were taken for the study. A total of 65 animals groups were divided into different groups and were provided with commercially available rodent diet and water ad libitum and kept under highly hygienic conditions in the animal house facilities. The mice were kept under controlled humidity, temperature $\left(25 \pm 2{ }^{\circ} \mathrm{C}\right)$ and diurnal cycle of 14 : $10 \mathrm{~h}$. All experiments were conducted according to ethical norms provided by CPCSEA India (permission No. CPCSEA/CH/RF/ACK-2003). 2,3,7,8 TCDD was obtained from Sigma-Aldrich Chemicals Pvt. Ltd. (CAS No. 1746-01-6). All other chemicals used for this study were of analytical grade. Different groups of mice were administered of TCDD $(0.004 \mathrm{mg} / \mathrm{kg} \mathrm{bw} / \mathrm{d}, 0.04 \mathrm{mg} / \mathrm{kg} \mathrm{bw} / \mathrm{d})$ dissolved in corn oil (vehicle) for three different exposure durations of 2, 4 and 6 days. The selection of the doses were based on the available reports of the doses causing effects on enzymatic activity in the vital tissues of mice, acute to sub-acute exposure and 
evaluation of toxicity studies and application of factors (LOAEL) for extrapolating from animal model to human for TCDD administered through oral route ${ }^{[8]}$. The doses selected for the study were very low concentration of TCDD and comparable to that of the human exposure through different environmental sources.

Kidney tissue from at least three animals for each dose group was suspended in chilled SucroseEDTA-Imidazole (SEI) buffer (pH 7.1) to remove blood and other membranous substances. Known amount of tissue was sampled from the pooled kidney tissues and homogenized in chilled phosphate buffer ( $\mathrm{pH}$ 7.0) to obtain a $10 \%(\mathrm{w} / \mathrm{v})$ homogenate. Enzyme extract preparation for purified lysosomal enzymes was carried out by the method of Beaufay ${ }^{[9]}$. The homogenate was then centrifuged at $2000 \mathrm{rpm}$ for $8 \mathrm{~min}$ at $4^{\circ} \mathrm{C}$. The obtained supernatant was re-suspended in phosphate buffer and centrifuged at 11,000 rpm for 40 minutes. The resultant sediment was re-suspended in phosphate buffer with $0.1 \%$ Triton X 100 to obtain a supernatant of lysosomal fraction. The specific activity of Acid Phosphatase, $\alpha$-Galactosidase, $\beta$-Glactosidase and $\beta$-Glucuronidase were estimated using this lysosomal fraction. The enzyme assays were done as per the method of Tettamanti and Masserini ${ }^{[10]}$. Protein concentration of the tissue homogenate was determined by the method of Lowry et $\mathrm{al}^{[11]}$, using bovine serum albumin as the standard. The obtained data were subjected to different statistical analyses like one-way and two-way nested ANOVA and ' $t$ ' test for their cumulative acceptability and hypotheses testing. All statistical analyses were done as per Sokal and Rohlf ${ }^{[12]}$.

\section{Results And Discussion}

Results of the present study showed drastic changes in the specific activity of lysosomal enzymes exposed to the doses of TCDD for all exposure duration in kidney cells of mice. The specific activity of acid phosphatase showed inhibitory trend in highest dose and exposure duration followed by slight stimulation after 4 days of exposure duration in lower dose (Fig. 1). Similarly, the specific activity of $\alpha$ - galactosidase showed inhibitory trend in higher dose of TCDD after 6 days of exposure. However, slight stimulatory effect were observed in lower dose of TCDD exposed for 2 days (Fig. 1). The specific activity of $\beta$ - galactosidase showed stimulation in higher dose of TCDD and exposed for 2, 4 and 6 days whilst, lower dose of TCDD showed inhibition in all exposure durations (Fig. 1). The specific activity of $\beta$-glucuronidase showed inhibitory trend in all exposure duration after the exposure in both the doses of TCDD (Fig. 1).

As the studies of the dose and duration dependent effects of TCDD on mammalian lysosomal enzymes are rare, the purpose of this study was to examine the very early effect of very low doses of TCDD to lysosomal enzymes more closely. The result suggests that the TCDD caused rapid changes in the specific activity of key lysosomal enzymes in kidney cells of mice. Dioxin like compounds are highly toxic environmental stressors that accumulated in lipid rich tissue of human and wildlife and relevant symptoms of renal disease were seen especially during starvation ${ }^{[13,14]}$. The intracellular accumulation of TCDD and its byproducts or free molecules of TCDD was reported to be depended mainly on the exposure time and secondarily on the dose of toxicant pumped into the animal ${ }^{[15]}$. Lysosome is recognized as intracellular catabolic center for different chemical reactions. Most of the environmental endocrine disruptors are accumulated within lysosome of kidney cells especially in the proximal convoluted tubule cells, where it may trigger cell proliferation and cell growth ${ }^{[16]}$. TCDD and few other dioxin like compounds induce formation of toxic proteins which might have created the intracellular toxic load. TCDD, PCBs and other PAH chemicals are reported to be interacting with AhR which can initiate the formation of apoptosome or trigger apoptosis ${ }^{[17]}$. Though it is not very clear at this moment but the results of the present study indicated the observed nephrotoxicity by TCDD was probably caused by some byproduct or intermediate compounds produced elsewhere. These compounds were transported to kidney and ultimately accumulated in lysosome or endocytosed, degraded by lysosome ${ }^{[18-19]}$. TCDD affects the signal pathway after binding with AhR receptor in cytosol ${ }^{[20]}$ and induce enzymatic activity such as phenobarbital ${ }^{[21,}$ ${ }^{22]}$. The results of two way nested ANOVA showed a clear exposure duration dependent effects of TCDD in almost all the enzymes estimated, except $\beta$-glucuronidase. $\beta$-glucuronidase showed highly significant dose and duration dependent effects of TCDD (Table 1). The observed results indicated that even very low doses of TCDD can alter the lysosomal enzyme stability in kidney cells. On the other hand, the results of ' $t$ ' tests showed significant variations in the activities of key lysosomal enzymes over their respective controls. Highly significant variations in the specific activity of $\alpha$-galactosidase were observed after the exposure of higher dose of TCDD (Table 2). Similar results were also observed in one way ANOVA between individual exposure duration within each dose group (Table 3). The present study indicated that the cytotoxic effects of lipophilic TCDD might have altered the morphological and functional aspects of lysosomal enzyme studied. It has been reported that the ROS, or oxidative stress produced by environmental stressors, activate the caspase 3 or 9 . This caspases are activate the preliminary process of apoptosis through alteration of signaling pathway in kidney cells [23]. The observed results are in accordance with the report that the functional integrity of lysosomal is generally the common target for most environmental stressors ${ }^{[24]}$. Dysfunctions of lysosomal enzymes are related with many pathological conditions associated with toxic and degenerative renal disease ${ }^{[25]}$. The observed results are also in accordance with the fact reported earlier that TCDD induces expression of CYP1A1 protein ${ }^{[26]}$, altered 
intracellular volume of cell that affects the metabolic pathways where metabolism of different macromolecules might have arrested ${ }^{[27,28]}$. Thus, the intracellular ROS induces lipid peroxidation and conversion of fatty acid via lipooxygenase pathway, inhibiting receptor mediated mechanism in glomerular mesangium ${ }^{[29]}$. The predominant exposure duration dependent disturbances in the specific activities of the selected lysosomal enzymes in the present study possibly indicating a disturbances in cellular homeostasis which may affect various cellular functions ${ }^{[30,31]}$. These organochlorine pollutants are lipophilic and tend to accumulates in adipose tissue so symptoms relevant to toxicity manifest after starvation condition of living organism ${ }^{[32-34]}$. The alterations in the enzyme activities possibly showed cell defense toward incoming ROS which might have formed outside renal cells ${ }^{[35]}$.

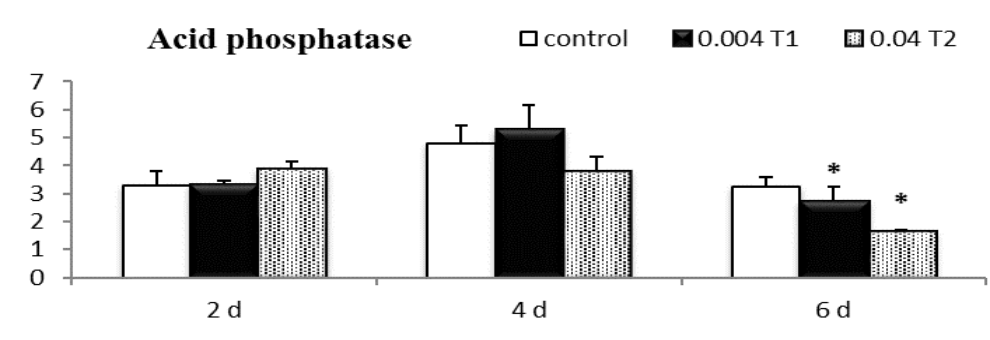

a- galactosidase

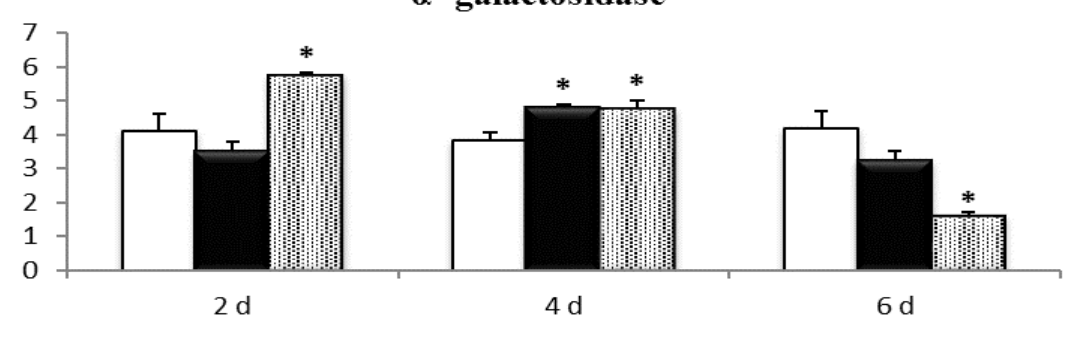

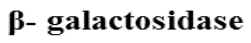

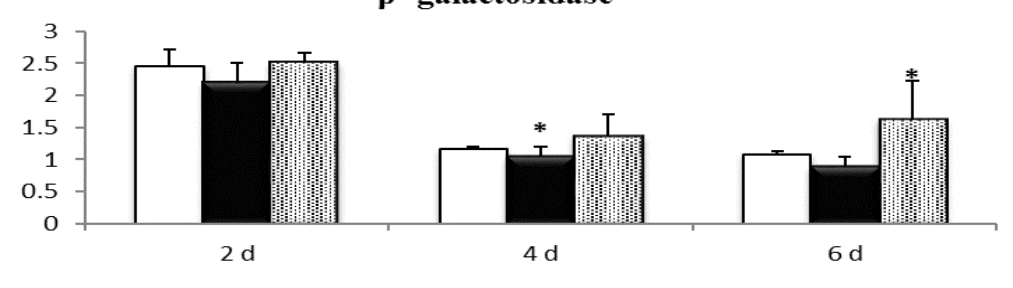

ß- glucuronidase

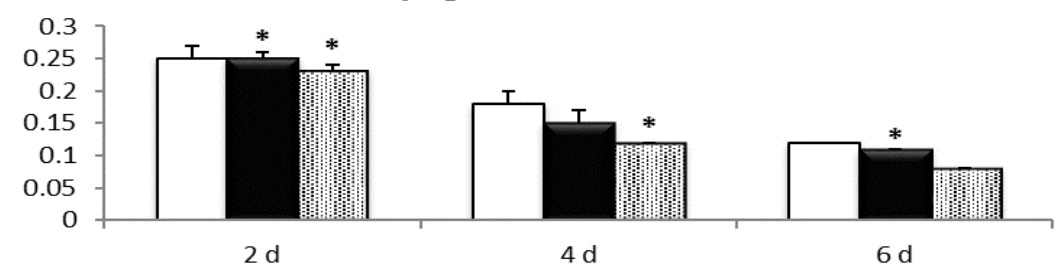

Fig.1. Histograms showing dose and duration dependent alterations in the specific activity of different lysosomal enzymes after in vivo TCDD intoxication. Error bars represent standard deviation and '*' sign represents the significant variations at $\mathrm{p}=0.05$ level. $\mathrm{T}_{1} \& \mathrm{~T}_{2}$ represent toxicated groups.

TABLE 1. Results of two-way nested ANOVA between control and toxicated groups.

\begin{tabular}{|c|c|c|c|c|}
\hline & Acid Phosphatase & $\alpha$-Galactosidase & $\beta$-Galactosidase & $\beta$-Glucuronidase \\
\hline Amongst doses & 0.35 & 1.57 & 0.07 & $3.68^{*}$ \\
\hline Within durations & $12.40^{* *}$ & $12.49^{* *}$ & $24.75^{* *}$ & $52.10^{* *}$ \\
\hline
\end{tabular}

*Significance at $\mathrm{P}=0.05(\mathrm{~F}$ crit of $\mathrm{dF}=3,8)=3.63$

$* *$ Significance at $\mathrm{P}=0.05$ ( $\mathrm{F}$ crit of $\mathrm{dF}=8,35)=2.59$

TABLE 2. Results of t-test between control and individual TCDD exposure durations within each dose group, in kidney tissue of mice. 
Dose and duration dependent toxicity of Dioxin (2,3,7,8 TCDD) to few lysosomal enzymes in mice

\begin{tabular}{|c|c|c|c|c|c|c|c|c|}
\hline & \multicolumn{2}{|c|}{ Acid Phosphatase } & \multicolumn{2}{c|}{$\boldsymbol{\alpha}$ - Galactosidase } & \multicolumn{2}{|c|}{$\boldsymbol{\beta}$-Galactosidase } & \multicolumn{2}{|c|}{$\boldsymbol{\beta}$-Glucuronidase } \\
\hline & $\mathbf{0 . 0 0 4} \mathbf{~} \mathbf{g}$ & $\mathbf{0 . 0 4} \mathbf{~} \mathbf{g}$ & $\mathbf{0 . 0 0 4} \mathbf{~} \mathbf{g}$ & $\mathbf{0 . 0 4} \mathbf{~} \mathbf{g}$ & $\mathbf{0 . 0 0 4} \mathbf{~ m g}$ & $\mathbf{0 . 0 4} \mathbf{~ m g}$ & $\mathbf{0 . 0 0 4} \mathbf{~ m g}$ & $\mathbf{0 . 0 4} \mathbf{m g}$ \\
\hline $\mathbf{2}$ days & 0.11 & 1.81 & 1.78 & $3.18^{*}$ & 1.07 & 0.31 & $7.43^{*}$ & $5.58^{*}$ \\
\hline 4days & 0.79 & 2.04 & $7.02^{*}$ & $5.05^{*}$ & $2.84^{*}$ & 1.49 & 0.53 & $4.01^{*}$ \\
\hline 6 days & $5.73^{*}$ & $2.81^{*}$ & 1.14 & $7.86^{*}$ & 1.85 & $3.63^{*}$ & $3.88^{*}$ & 1.94 \\
\hline
\end{tabular}

*Significance at $\mathrm{P}=0.05$ (F crit $=2.77)$

TABLE-3. Results of one-way ANOVA between individual exposure duration within each dose group.

\begin{tabular}{|c|c|c|c|c|}
\hline & Acid Phosphatase & $\boldsymbol{\alpha}$-Galactosidase & $\boldsymbol{\beta}$-Galactosidase & $\boldsymbol{\beta}$-Glucuronidase \\
\hline Control & 8.70 & 0.45 & 67.73 & 45.78 \\
\hline T1 (0.004) & $28.82^{*}$ & $5.27^{*}$ & $25.58^{*}$ & $6.48^{*}$ \\
\hline T2 (0.04) & $11.97^{*}$ & $70.19^{*}$ & $28.55^{*}$ & 2.21 \\
\hline
\end{tabular}

*Significance at $\mathrm{P}=0.05$ (F crit $=5.14)$

\section{Conclusion}

The overall results indicated that even very low and environmentally available concentration of TCDD provoked dose and duration dependent effects on key lysosomal enzymes studied. TCDD altered the lysosomal enzyme stability and possibly produce intracellular reactive oxygen species. These ROS might be responsible for an increase in the intracellular ions. Though it is not very clear at this point, but all these effects cumulatively might have initiated the preliminary process for cell damage and possibly cell apoptosis.

\section{Acknowledgements}

Authors are thankful to UGC, Govt. of India, New Delhi for supporting this study through its DSA/CAS programme. The senior author is thankful to UGC, New Delhi for providing Meritorious fellowship.

\section{References}

[1]. Schwetz BA, Norris JM and Sparschu GL, Toxicology of chlorinated dibenzo-p-dioxins, Environmental Health Perspectives, 5, 1973, 87-99.

[2]. Kimbrough RD and Houk VN, Effects of chlorinated dibenzodioxins, ACS Symposium Series, 338, 1987, 68.

[3]. Poland A and Glover E, Chlorinated dibenzo-p-dioxins: potent inducers of 6-aminolevulinic acid synthetase and aryl hydrocarbon hydroxylase. II. A study of the structure-activity relationship, Molecular Pharmacology, 9, 1973, 736.

[4]. Safe S, Polychlorinated biphenyls (PCBs), dibenzo-p-dioxins (PCDDs), dibenzofurans (PCDFs), and related compounds: environmental and mechanistic considerations which support the development of toxic equivalency factors (TEFs), Critical Reviews in Toxicology, 21, 1990, 51 .

[5]. U.S. EPA, Ambient water quality criteria for 2,3,7,8-tetrachlorodibenzo-p-dioxin. Office of Water Regulations and Standards, Criteria and Standards Division, Washington, DC. EPA 440/5-84-007, 1984.

[6]. Lin CH, Juan SH, Wang CY, Sun YY, Chou CM, Chang SF, Hu SY, Lee WS and Lee YH, Neuronal activity enhances aryl hydrocarbon receptor-mediated gene expression and dioxin neurotoxicity in cortical neurons, Journal of Neurochemistry, 104, 2008, 1415.

[7]. Fiorito F, Irace C, Pascale AD, Colonna A, Lovone G, Pagnini U, Santamaria R \& Martino LD, 2,3,7,8-tetrachlorodibenzo-p-dioxin induced autophagy in a bovine kidney cell line, Toxicology, 290, 2011,258.

[8]. ATSDR, Toxicological profile for chlorinated dibenzo- p- dioxins, U.S. Department of Health and Human Services, Public Health Services, Atlanta, GA, 1998.

[9]. Beaufay H, Methods for the isolation of lysosomes. Edited by J T Dingle, Lysosomes: A Laboratory Handbook, (North-Holland Publ. Co. Amsterdam), 1972, 1.

[10]. Tettamanti G and Masserini M, Beta mannosidase. In: methods of enzymatic analysis vol. IV III eds edited by Bergmeyer H.U. (Verlag Chemie, Weinheim, Deerfield beach, Florida, Basel), 1984, 241.

[11]. Lowry OH, Rosebrough NJ, Farr AL and Randall RJ, Protein measurement with the folin phenol reagent. Journal of Biological Chemistry, 193, 1951265.

[12]. Sokal RR and Rohlf FJ, Biometry. San Francisco. WH Freeman and Company. 1969.

[13]. Tilson HA and Kodavanti PR, The neurotoxicity of polychlorinated biphenyls, Neurotoxicology, 19, 1998, 517.

[14]. Venkataraman P, Muthuvel R, Krishnamoorthy G, Arunkumar A, Sridhar M, Srinivasan N, Bala subramanian K, Aruldhas MM and Arunakaran J, PCB (Aroclor 1254) enhances oxidative damage in rat brain regions: protective role of ascorbic acid, Neurotoxicology, 28, 2007, 490.

[15]. Norback DH and Allen JR, Biological responses of the nonhuman primate, chicken, and rat to chlorinated dibenzo-p-dioxin ingestion. Enviromental Health Perspecives, 5, 1973, 233.

[16]. Orrenius S, Kaminskyy OV and Zhivotovsky B. Autophagy in Toxicology: cause or consequences, 53 2013, 275.

[17]. Narayanan PK, Carter WO, Ganey PE, Roth RA, Voytik Harbin SL and Robinson JP, Impairment of human neutrophil oxidative burst by PCBs inhibition of superoxide dismutase activity, Journal of Leukocyte Biology, 63, 1998, 216.

[18]. Cain K and Holt DE, Studies of cadmium-theonin induced neuropathy, Time course of cadmium-threonin uptake and degradation, Chemico-Biological Interaction, 43, 1983223. 
[19]. Klassen CD and Amdur MD (eds), Casarett and Doull's Toxicology, $3^{\text {rd }}$ edition New York. Macmillan Co. Inc. The chlorophenoxy herbicides have produced contact dermatitis in man, 1986, p 554.

[20]. Kannan N, Tanabe S, Ono M and Tatsukawa R, Critical evaluation of polychlorinated biphenyl toxicity in terrestrial and marine mammals: increasing impact of non-ortho and mono-ortho coplanar polychlorinated biphenyls from land to ocean, Archives of Environmental Contamination Toxicology, 18, 1989, 850.

[21]. Safe SH, Polychlorinated biphenyls (PCBs): environmental impact, biochemical and toxic responses, and implications for risk assessment, Critical Reviews in Toxicology, 24, 1994, 87.

[22]. Zoeller RT, Dowling AL and Vas AA, Developmental exposure to polychlorinated biphenyls exerts thyroid hormone-like effects on the expression of $\mathrm{RC} 3 /$ neurogranin and myelin basic protein messenger ribonucleic acids in the developing rat brain. Endocrinology, 141, 2000, 181.

[23]. Garrido MB, Didelot C, Zermati Y, Schmitt E and Kroemer G, "Heat shock proteins 27 and 70: anti-apoptotic proteins with tumorigenic properties," Cell Cycle, 5, 2006, 2592.

[24]. Cuervo AM, Autophagy: in sickness and in health. Trends in Cell Biology, 14, 2004,70.

[25]. Broeg K, The activity of macrophage aggregates in the liver of flounder (Platichthys flesus) and wrasse (Symphodus melops) is associated with tissue damage Marine Environmental Research, 69, 2010, 14.

[26]. Ma Q and Lu AY, CYP1A induction and human risk assessment: an evolving tale of in vitro and in vivo studies, Drug Metabolism and Disposition, 35, 2007, 1009.

[27]. Chen ZH, Hurh YJ, Na HK, Kim JH, Chun YJ, Kim DH, Kang KS, Cho MH and Surh YJ, Resveratrol inhibits TCDD-induced expression of CYP1A1 and CYP1B1 and catechol estrogenmediated oxidative DNA damage in cultured human mammary epithelial cells. Carcinogenesis 25, 2006, 1579-85.

[28]. Moennikes O, Loeppen S, Buchmann A, Andersson P, Ittrich C, Poellinger L and Schwarz M, A constitutively active dioxin/ aryl hydrocarbon receptor promotes hepatocarcinogenesis in mice, Cancer Research 64, 2004, 4707.

[29]. Baud and Ardaillon, Leukotrienes and reactive oxygen species as mediators of glomerular injury, American Journal of Nephrology, 9, $1989,17$.

[30]. Jigyasi J and Kundu R, Low dose TCDD affects membrane bound ion dependent ATPases in mice liver, IOSR Journal of Environmental Science Toxicology and Food Technology, 2, 2013a,15-19

[31]. Pathak S and Kundu R, Effects of low concentration of a polychlorinated biphenyls, arochlor 1254 on membrane bound ion dependent ATPases in mice liver, Indian Journal of Experimental Biology, 51(6), 2013b, 477-80.

[32]. Pathak S and Kundu R, Short-term PCB (Aroclor 1254) toxicity on few phosphatases in mice brain, Dose Response, 11(1), 2013a, $1-8$

[33]. Jigyasi J and Kundu R, Effects of low dose dioxin on membrane bound ion dependent ATPases in mice kidney, IOSR Journal of Environmental Science Toxicology and Food Technology, 2(5), 2013b, 43-48.

[34]. Pathak S and Kundu R, Low doses of a PCB (Aroclor 1254) affect the body weight by decreasing the activity of Glucose-6Phosphatase in the liver and kidney cells of mice, IOSR. Journal of Environmental Science Toxicology and Food Technology, 3(1), 2013b, 16-21.

[35]. Pathak S and Kundu R, Low concentration of Aroclor 1254 affects membrane bound ion dependent ATPases in mice kidney, Bioscan, 8(1), 2013c, 1-10 